\title{
Effect of Controlled Cooling on Microstructure and Tensile Properties of Low C Nb-Ti-Containing HSLA Steel for Construction
}

\author{
Yi Fan ${ }^{1,2}$, Qian Wang ${ }^{1,3}$, Hongwu Liu ${ }^{1,3}$, Tongliang Wang ${ }^{2}$, Qingfeng Wang ${ }^{1,3, *}$ and \\ Fucheng Zhang ${ }^{1,3}$ \\ 1 Laboratory of Metastable Materials Science and Technology, Yanshan University, Qinhuangdao 066004, \\ China; ljclr653517@163.com (Y.F.); wq986086441@139.com (Q.W.); liuhongwu0335@163.com (H.L.); \\ zfc@ysu.edu.cn (F.Z.) \\ 2 Research Institue of Nanjing Iron \& Steel Co., Ltd., Nanjing 210035, China; wtlsars@163.com \\ 3 National Engineering Research Center for Equipment and Technology of Cold Strip Rolling, \\ Yanshan University, Qinhuangdao 066004, China \\ * Correspondence: wqf67@ysu.edu.cn; Tel.: +86-335-2039067
}

Academic Editor: Hugo F. Lopez

Received: 16 November 2016; Accepted: 4 January 2017; Published: 12 January 2017

\begin{abstract}
The thermo-mechanical control processing (TMCP) of low carbon (C) Nb-Ti-containing HSLA steel with different cooling rates from 5 to $20^{\circ} \mathrm{C} / \mathrm{s}$ was simulated using a Gleeble 3500 system. The samples' microstructure was characterized and the tensile properties measured. The results show that a microstructure mainly consisting of quasi-polygonal ferrite (QPF), granular bainitic ferrite (GBF), and martensite/austenite (M/A) constituent formed in each sample. Furthermore, the accelerated cooling led to a significant grain refinement of the QPF and GBF, and an increase in the density of dislocations, as well as suppressed the precipitation of nanoscale particles; however, the overall yield strength $(Y S)$ still increased obviously. The accelerated cooling also brought about a decrease in amount of M/A constituent acting as a mixed hard phase, which weakened the overall strain-hardening capacity of the QPF + GBF + M/A multiphase steel and simultaneously elevated yield-to-tensile strength ratio $(Y R)$. In addition, the mechanisms in dominating the influence of controlled cooling on the final microstructure and tensile properties were discussed.
\end{abstract}

Keywords: HSLA construction steels; controlled cooling; microstructure; tensile properties; strain-hardening

\section{Introduction}

High strength low alloy (HSLA) steel with a low yield-to-tensile strength ratio (YR) can inhibit an unexpected failure due to its high resistance to deformation from yielding to plastically destabilizing [1]. For this reason, HSLA steel for earthquake resistant construction normally requires a combination of high strength and low $Y R$ [2]. However, since high strength of plate steel due to fine-grained microstructure is basically correlated to high $Y R$, it is difficult to produce such a high strength plate steel with low $Y R[2,3]$. Furthermore, HSLA construction steel is currently produced by thermo-mechanical control processing (TMCP) of low carbon containing steel [4], leading to a highly grain-refined microstructure. Hence, an enhanced combination of weldablility, strength and toughness can be achieved at the expense of an elevated $Y R[4,5]$. Extensive investigations [2,6-8] have indicated that an appropriate dual-phase microstructure containing granular bainitic ferrite (GBF) and/or quasi-polygonal ferrite (QPF) and M/A constituent is essential to balance the above described yield strength and $Y R$ in plate steel produced by TMCP. An increased amount of M/A constituent acting as a mixed hard phase [9-12] can enhance the stain-hardening capacity of the soft ferrite 
phase $[2,6-8,13]$ and correspondingly lower the $Y R$, which has been achieved by the addition of nitrogen to V-microalloyed steel [8], and the accelerated cooling followed by heat-treatment on-line process (HOP) of Nb-microalloyed steel [6,7]. Nevertheless, the M/A constituent acting as brittle islands can cause a toughness loss [14-16], which can be prevented by grain refinement of soft ferrite phase [17]. Mixed microstructure of suitably fine-grained QPF and/or GBF as the soft phase and an increasing amount of $\mathrm{M} / \mathrm{A}$ constituent as the mixed hard phase, may also form in a low carbon $\mathrm{Nb}$-Ti-containing HSLA steel, and the tensile properties of this type of multiphase plate steel are characterized by a combination of high strength and low $Y R$. This multiphase plate steel may be prepared through an appropriate control of cooling route suitable for industrial process. However, the mechanisms in governing the overall tensile properties required for the development of such an advanced multiphase HSLA plate steel need further investigation in detail.

As such, in this attempt, the simulations on TMCP of low-carbon Nb-Ti containing HSLA steel with different controlled cooling rates were performed. The effect of controlled cooling on the microstructure and tensile properties of all the samples was evaluated.

\section{Experimental Materials and Methods}

Low carbon $\mathrm{Nb}$-Ti-containing steel was melted in a $50 \mathrm{~kg}$ vacuum furnace and hot-rolled to 16-mm-thick plates, with the chemical compositions listed in Table 1. The steel contains $0.06 \mathrm{C}, 1.47 \mathrm{Mn}$, $0.20 \mathrm{Mo}, 0.23 \mathrm{Cr}, 0.25 \mathrm{Ni}$ and $0.19 \mathrm{Cu}$ (in wt. \%); these elements serve to promote the formation of QPF and/or GBF containing M/A constituent. Furthermore, a small amount of $\mathrm{Nb}$ and Ti was added to prevent the coarsening of austenite grains during the subsequent TMCP.

Table 1. Chemical compositions of experimental steel (wt. \%).

\begin{tabular}{cccccccccccc}
\hline $\mathbf{C}$ & $\mathbf{S i}$ & $\mathbf{M n}$ & $\mathbf{P}$ & $\mathbf{S}$ & $\mathbf{C r}$ & $\mathbf{N i}$ & $\mathbf{M o}$ & $\mathbf{C u}$ & $\mathbf{N b}$ & $\mathbf{T i}$ & $\mathbf{A l}_{\mathbf{S}}$ \\
\hline 0.06 & 0.28 & 1.47 & 0.008 & 0.002 & 0.23 & 0.25 & 0.20 & 0.19 & 0.035 & 0.018 & 0.024 \\
\hline
\end{tabular}

Round bar specimens with length $\times$ diameter of $\Phi 75 \times 15 \mathrm{~mm}$ were cut from the plates, and thermo-mechanically processed using a Gleeble 3500 system; the process routings are shown schematically in Figure 1. A group of specimens was produced by diffusion annealing at $1180^{\circ} \mathrm{C}$ for $10 \mathrm{~min}$, compressing at $1080^{\circ} \mathrm{C}$ for a strain of 0.35 to simulate rough rolling, subsequently compressing at $830{ }^{\circ} \mathrm{C}$ for a strain of 0.30 to simulate finish rolling, and finally controlled cooling. The average strain rate for both compressions was $1 \mathrm{~s}^{-1}$. The controlled cooling processes were conducted with commencing at $780{ }^{\circ} \mathrm{C}$, cooling to $450{ }^{\circ} \mathrm{C}$ at four different rates of $5-20{ }^{\circ} \mathrm{C} / \mathrm{s}$, re-reddening up to $500{ }^{\circ} \mathrm{C}$ for promoting the carbon atom diffusion from $\alpha$ to metastable austenite $\left(\gamma^{\prime}\right)$, and air-cooling to room temperature.

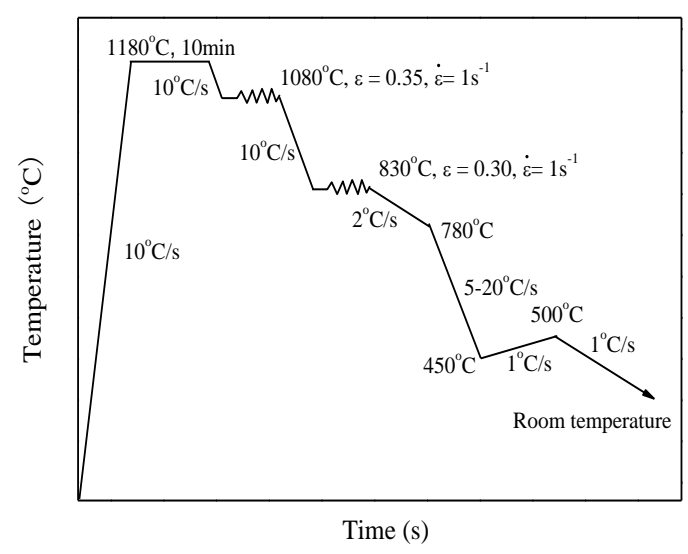

Figure 1. Schematic illustration of simulation schedule for thermal-mechanical controlled processing. 
After the simulation, each sample for microstructural observations was cut along the cross-section where the thermocouple was located, polished, and etched in a $4 \%$ nital solution. The microstructure was observed via optical microscopy (OM) using an Axiover-200MAT microscope (Axiover, Jean, Germany). In addition, the M/A constituent was further characterized using metallographic samples etched in LePera's reagent. The morphology of M/A constituent (in white) dispersed in the ferrite matrix (in gray) was estimated at $500 \times$, and quantified from more than 500 particles in at least ten fields of view, using the Image-Pro Plus ${ }^{\mathrm{TM}}$ software (Media Cybernetics, Rockville, MD, USA). Furthermore, the ferrite matrix, M/A constituent, dislocations, and precipitate in each sample were characterized using a JEM-2010 transmission electron microscope (TEM, JEOL, Tokyo, Japan). The average size and volume fraction of the precipitated particles were also measured statistically by averaging over at least 1000 particles from the TEM image. Each sample for TEM observations was obtained by cutting thin slice parallel to the metallographic section, and the 3-mm-diameter disc made by a small punch was then thinned via electropolishing. The electropolishing was performed at a voltage and current of $25 \mathrm{~V}$ and 55-65 mA, respectively, using a 7\% perchloric acid/glacial acetic acid mixture under room temperature.

The fraction of retained austenite (RA) and the density of dislocations in each sample were determined via quantitative X-ray diffraction (XRD) analysis. The XRD spectra were obtained by scanning in a Rigaku D/max-2500/PC diffractometer (Rigaku, Tokyo, Japan) using a Cu-K $\alpha$ radiation

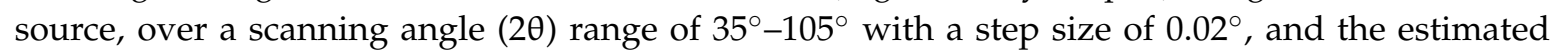
penetration depth was $20 \mu \mathrm{m}$ or so. For more precisely determining the low level of RA, six different sections of an identical sample were scanned and the average value was reported. A method offered by Ferreira et al. [18] was used to deal with the decomposition of XRD peaks and calculation. In addition, the X-ray method for determining dislocation density is based on the theory $[19,20]$ below. Diffraction peaks are broadened by the presence of non-uniform strains that systematically shift atoms from their ideal positions and finite size of coherently diffracting domains. These two effects have a different dependence on the value of $\theta$. The non-uniform strain effect can therefore be separated, since the slope of a plot of $\beta_{\mathrm{hkl}} \cos \left\{\theta_{\mathrm{hkl}}\right\}$ versus $4 \sin \left\{\theta_{\mathrm{hkl}}\right\}$ is equal to a measure of the non-uniform strain, $\varepsilon$. The parameter, $\beta$, is the measured peak broadening. The dislocation density, $\rho$, is calculated using the following equation [21]:

$$
\rho=\frac{6 \pi \varepsilon^{2}}{b^{2}}
$$

where $b$ stands for the Burgers vector of dislocations in $\alpha$-Fe. $\varepsilon$ and $b$ can be determined by XRD line profiles [20].

Moreover, the mean equivalent diameter (MED) of ferrite grains with boundaries defined by a misorientation tolerance angle (MTA) ranging $2^{\circ}-30^{\circ}$ was determined for each sample. To quantify the MED, each sample was electropolished in a solution of $85 \%$ alcohol, $10 \%$ perchloric acid, and $5 \%$ glycerinum. The electropolished sample was then examined via Electron backscatter diffraction (EBSD) performed on a ZEISS ULTRA 55 Field-Emission Scanning Electron Microscope (FESEM, Hitachi, Tokyo, Japan) equipped with a HKL EBSD fast acquisition system, using a step size of $0.12 \mu \mathrm{m}$ for the EBSD scans.

Tensile samples were made from each TMCP simulation specimen by cutting along the cross-section with the dimensions indicated in Figure 2. The room temperature tensile tests were carried out at an extension rate of $1 \mathrm{~mm} / \mathrm{min}$, using an Inspekt Table $3 \mathrm{KN}$ model universal testing machine and the special fixture [2]. Two tensile samples were tested for each TMCP simulation specimen and the average value is reported. The yield strength was determined as the $0.2 \%$ offset stress. 
(a)

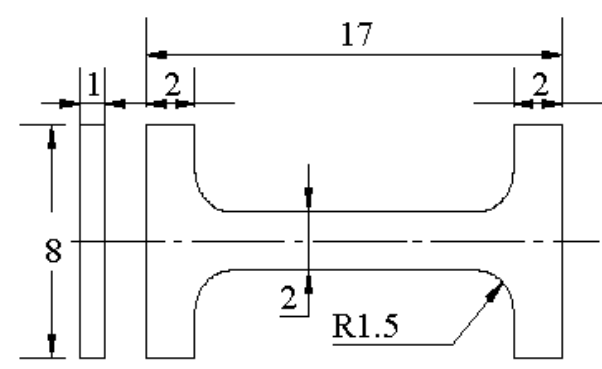

(b)

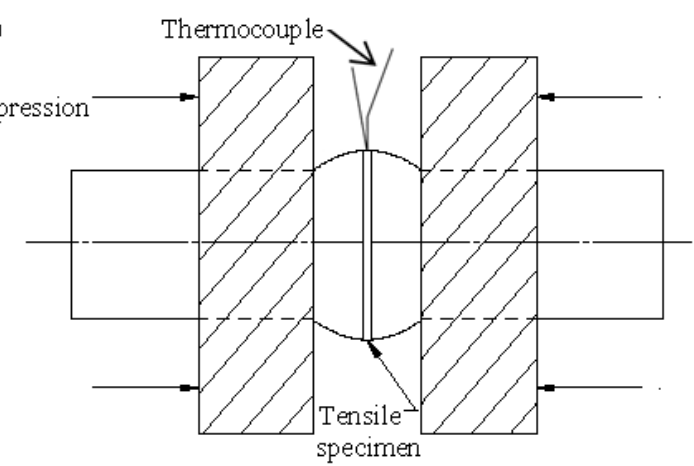

Figure 2. Wire-cut tensile sample (a) (in $\mathrm{mm}$ ) from the cross section of TMCP simulation specimen (b) with $10 \times 2 \mathrm{~mm}^{2}$ gauge length located in the center of the formerly compressed section.

\section{Results}

\subsection{Tensile Properties}

The typical tensile strain-stress curves are shown in Figure 3 with the tensile properties listed in Table 2. As the table indicates, the yield strength $(Y S)$ increases from 476 to $537 \mathrm{MPa}$, while the ultimate tensile strength (TS) also increases from 675 to $692 \mathrm{MPa}$, with an increase in cooling rate from 5 to $20^{\circ} \mathrm{C} / \mathrm{s}$. Accordingly, the strain hardening magnitude, $\Delta \sigma$, which is equal to the difference between the TS and the $Y S$, decreases from 199 to $155 \mathrm{MPa}$, and the $Y R$ increases from 0.70 to 0.78 . The $\Delta \sigma$ and the $Y R$ are secondary criteria for the indication of strain hardening, and a high $\Delta \sigma$ or a low $Y R$ represents an excellent strain hardening capacity [22].

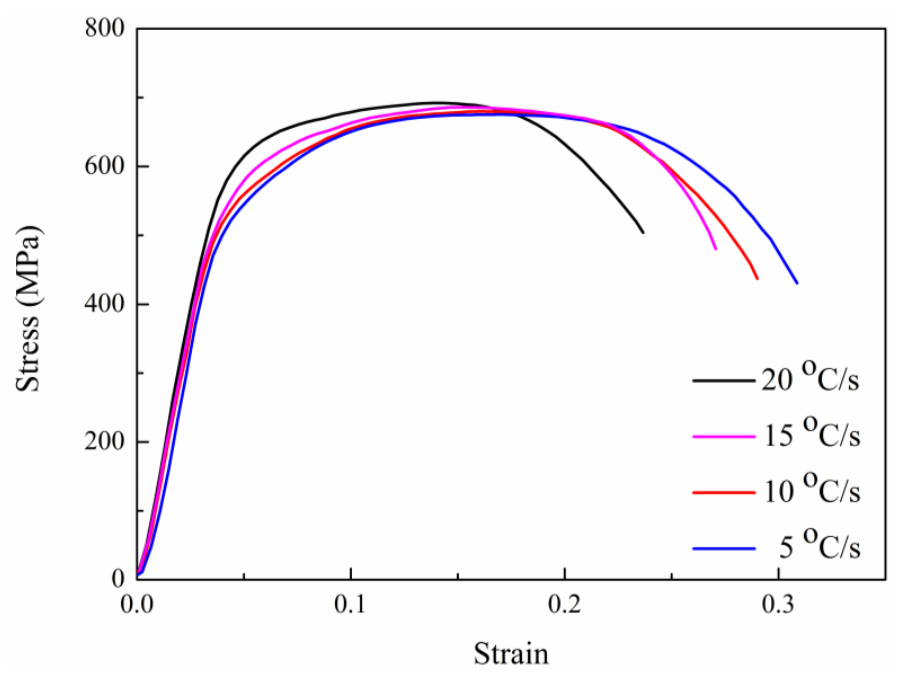

Figure 3. Typical tensile stress-strain curves for different nitrogen content steels.

Table 2. Summary of the tensile test results.

\begin{tabular}{ccccc}
\hline $\boldsymbol{C R} /{ }^{\circ} \mathbf{C}$ & $\boldsymbol{Y S} / \mathbf{M P a}$ & $\boldsymbol{T S} / \mathbf{M P a}$ & $\Delta \sigma / \mathbf{M P a}$ & $\boldsymbol{Y R}$ \\
\hline 5 & $476 \pm 11$ & $675 \pm 7$ & $199 \pm 9$ & $0.70 \pm 0.02$ \\
10 & $498 \pm 9$ & $680 \pm 6$ & $182 \pm 7$ & $0.73 \pm 0.01$ \\
15 & $521 \pm 10$ & $686 \pm 7$ & $165 \pm 8$ & $0.76 \pm 0.02$ \\
20 & $537 \pm 7$ & $692 \pm 5$ & $155 \pm 4$ & $0.78 \pm 0.01$ \\
\hline
\end{tabular}

$C R$-Cooling rate, $Y S$-yield strength, TS-tensile strength, $\Delta \sigma$-Strain hardening magnitude, and $Y R$-yield-to-tensile strength ratio. 


\subsection{Microstructure}

\section{Multiphase Microstructure Observations}

Typical optical micrographs displaying the microstructure (upper) and M/A constituent (lower) are shown in Figure 4, and the quantified features are summarized in Table 3. As the figure indicates, the microstructure of samples cooling at different rates is composed of QPF, GBF and a little lath bainitic ferrite (LBF), dispersed with M/A constituent. The two different morphologies of bainitic structure, i.e., GBF and LBF, are distinguished according to systematic descriptions by Bramfiti et al. [23] and Bhadeshia et al. [24]. The GBF as a transformation product during continuous cooling is essentially a mixture of blocky ferrite with dispersed granular constituent of martensite and retained austenite, which are more easily distinguished using Lepera's reagent etched sample. However, after the QPF and GBF formation ends, the LBF can form in the region of residual austenite with carbon in rich, yet not rich enough to produce $\mathrm{M} / \mathrm{A}$ constituent, and grows as sheaves with the transformation proceeding. The GBF forms mainly at the prior austenite grain (PAG) boundary and intragranular QPF. Moreover, the massive and slender M/A constituents are dispersed at the boundaries of the QPF, GBF, and even PAG. The amount of GBF increases gradually at the expense of the QPF with increased cooling rate. In addition, as the table shows, the area fraction, $f_{\mathrm{M} / \mathrm{A}}$, and average size of the $\mathrm{M} / \mathrm{A}$ constituent decreases from $7.7 \%$ to $3.5 \%$ and from 1.9 to $0.3 \mu \mathrm{m}$, respectively, with increased cooling rate; the amount of massive $\mathrm{M} / \mathrm{A}$ constituent also decreases, whereas its slender counterpart increases.

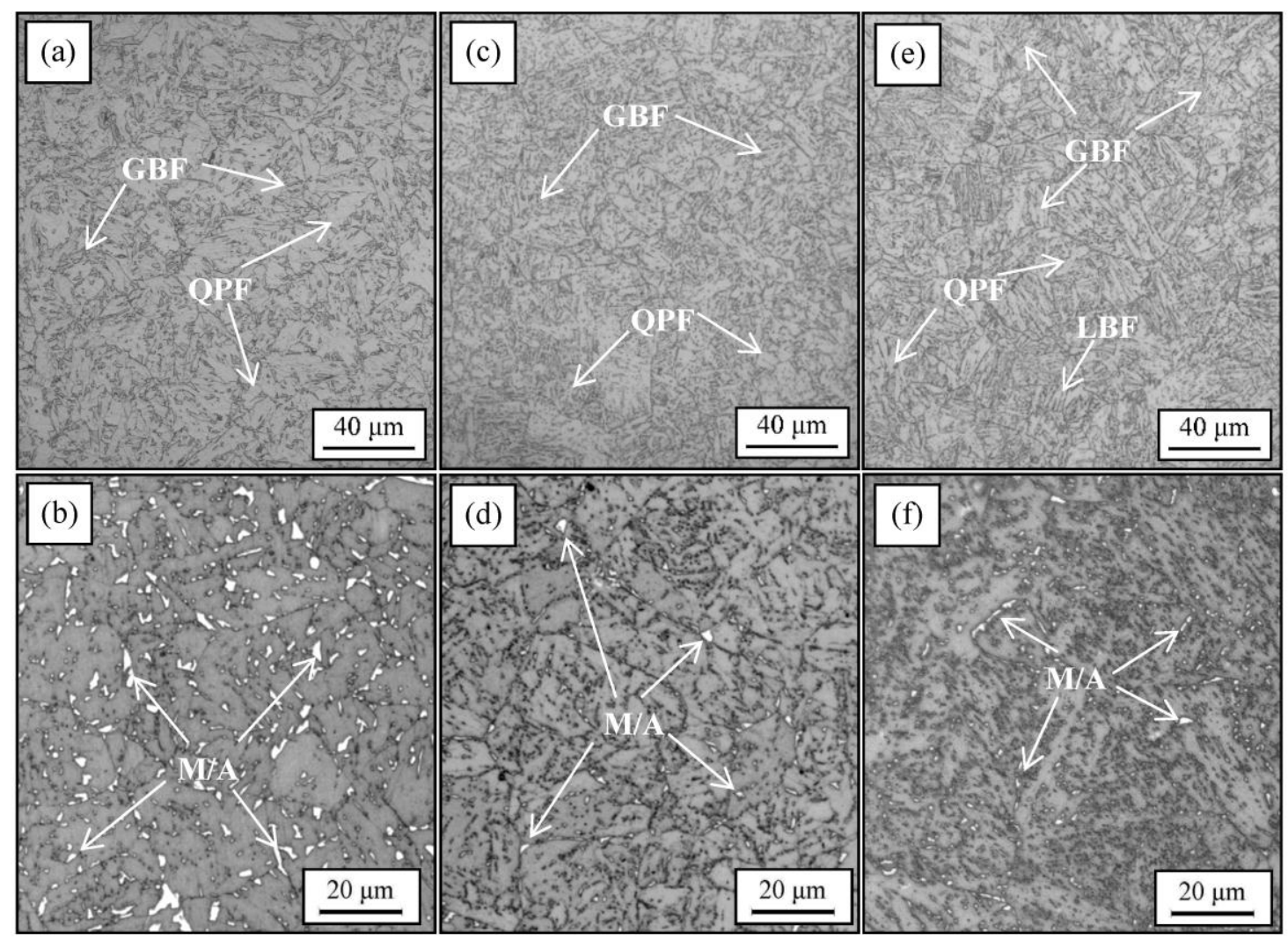

Figure 4. Optical micrographs of $4 \%$ Nital solution and Lepera's reagent etched samples of: $(\mathbf{a}, \mathbf{b}) 5{ }^{\circ} \mathrm{C} / \mathrm{s}$; (c,d) $15{ }^{\circ} \mathrm{C} / \mathrm{s}$; and (e,f) $20^{\circ} \mathrm{C} / \mathrm{s}$. QPF-quasi-polygonal ferrite, GBF-granular bainite ferrite, LBF-Lath bainite ferrite, $\mathrm{M} / \mathrm{A}$-Martensite/austenite constituent. 
Table 3. Summary of microstructure observations and quantifications.

\begin{tabular}{|c|c|c|c|c|c|c|c|c|c|}
\hline$C R^{\circ} \mathrm{C} / \mathrm{s}$ & Phase Composition & $f_{\mathrm{M} / \mathrm{A}} / \%$ & $f_{\mathrm{RA}} / \%$ & $\mathrm{C}_{\mathrm{M} / \mathrm{A}} / \mathrm{wt.} \%$ & $f_{2^{\circ}} \leq \theta \leq 15^{\circ} / \%$ & $\mathrm{MED}_{2^{\circ}} \leq \theta \leq 15^{\circ} / \mu \mathrm{m}$ & $D_{\mathrm{p}} / \mathrm{nm}$ & $f_{\mathrm{p}} / \%$ & $\rho / \times 10^{14} \mathrm{~m}^{-2}$ \\
\hline 5 & $\mathrm{QPF}+\mathrm{GBF}+\mathrm{M} / \mathrm{A}$ & $7.7 \pm 0.4$ & $0.76 \pm 0.17$ & 0.54 & 45 & 6.05 & $30.7 \pm 0.5$ & $5.6 \pm 0.3 \times 10^{-4}$ & $3.82 \pm 0.05$ \\
\hline 10 & $\hat{\mathrm{QPF}}+\mathrm{GBF}+\mathrm{M} / \mathrm{A}$ & $5.6 \pm 0.2$ & $1.28 \pm 0.15$ & 0.73 & 51 & 4.90 & $26.8 \pm 0.2$ & $3.0 \pm 0.4 \times 10^{-4}$ & $4.10 \pm 0.03$ \\
\hline 15 & $\mathrm{QPF}+\mathrm{GBF}+\mathrm{M} / \mathrm{A}$ & $4.1 \pm 0.3$ & $1.67 \pm 0.13$ & 1.00 & 54 & 3.71 & $22.6 \pm 0.3$ & $1.7 \pm 0.3 \times 10^{-4}$ & $4.21 \pm 0.06$ \\
\hline 20 & $\mathrm{QPF}+\mathrm{GBF}+\mathrm{LBF}+\mathrm{M} / \mathrm{A}$ & $3.5 \pm 0.2$ & $2.31 \pm 0.16$ & 1.16 & 59 & 3.37 & $20.4 \pm 0.3$ & $0.8 \pm 0.2 \times 10^{-4}$ & $4.39 \pm 0.04$ \\
\hline
\end{tabular}

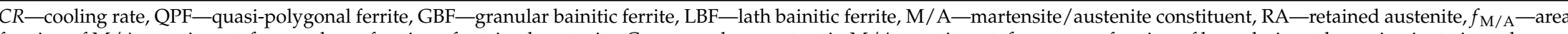
fraction of M/A constituent, $f_{\mathrm{RA}}$-volume fraction of retained austenite, $\mathrm{C}_{\mathrm{M} / \mathrm{A}}$-carbon content in M/A constituent, $f_{2^{\circ} \leq \theta \leq 15^{\circ}}$-fraction of boundaries at low misorientation tolerance angle $2^{\circ}-15^{\circ}, \mathrm{MED}_{2^{\circ}} \leq \theta \leq 15^{\circ}$ - mean equivalent diameter of ferrite grain with boundaries at low misorientation tolerance angle $2^{\circ}-15^{\circ}$, determined as effective grain size, $D_{\mathrm{p}}-$ average size of precipitates, $f_{\mathrm{p}}$-volume fraction of precipitates, $\rho$ - the density of dislocations. 
The typical TEM observations are exhibited in Figure 5. The ferrite plates formed from the parent austenite phase in each sample, while the island-like phase remained. The irregular plates of QPF have a relatively low dislocation density (Figure 5a,b), whereas the parallel plates comprising the GBF and a little LBF possess a high density of dislocations (Figure 5b,c), Furthermore, the bright (Figure 5d) and dark (Figure 5e) field images, as well as the selected area diffraction pattern (Figure 5f) reveal that the island is a constituent phase of martensite and austenite. All slender, and a part of the massive M/A constituent, are located at the boundaries of the GBF plates; the other massive constituent is dispersed in the regions surrounded by the QPF plates or between the QPF and GBF plates.
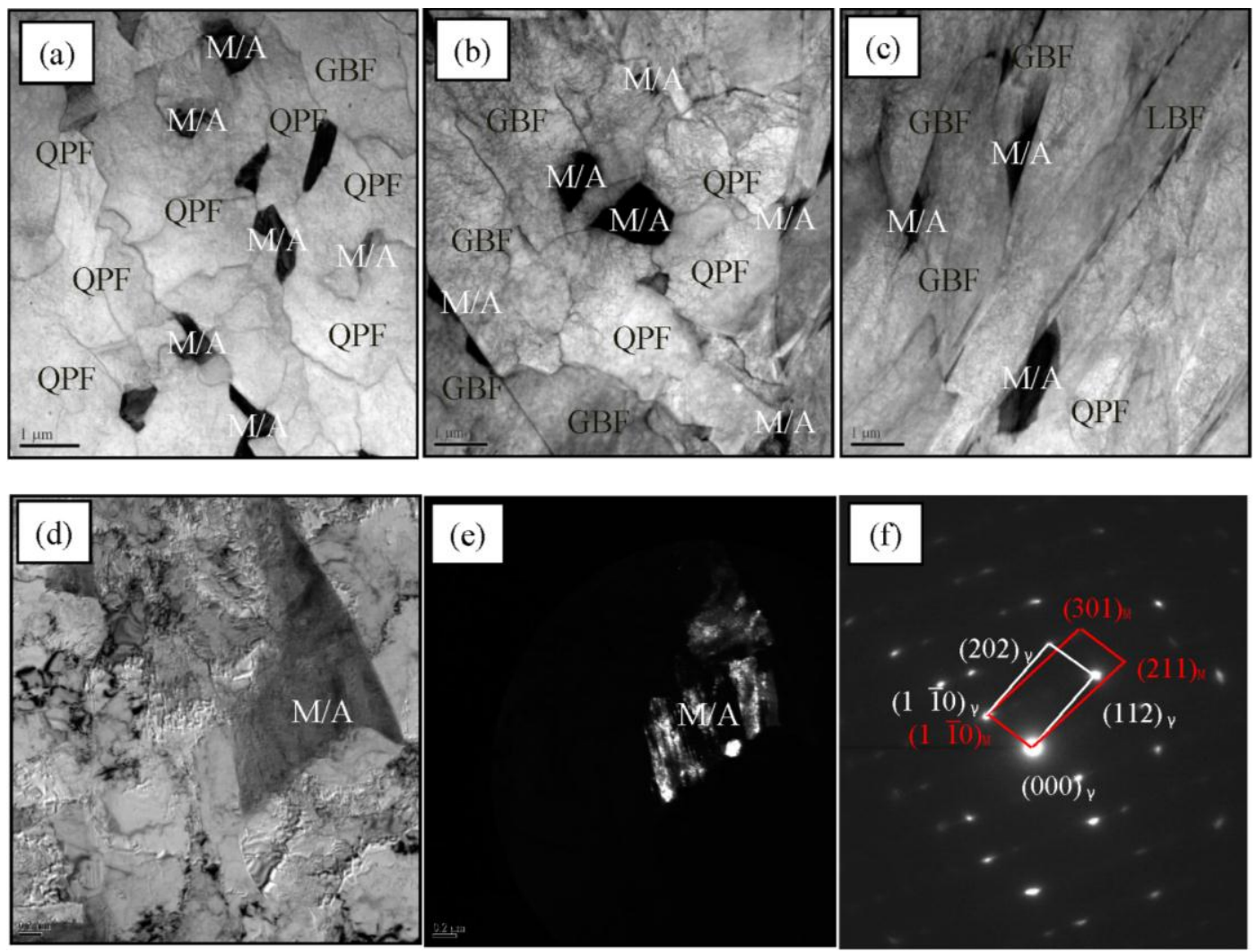

Figure 5. Typical TEM observations of GBF, AF and LBF plates with $\mathrm{M} / \mathrm{A}$ constituent in samples of: (a) $5{ }^{\circ} \mathrm{C} / \mathrm{s}$; (b) $15^{\circ} \mathrm{C} / \mathrm{s}$; and (c) $20^{\circ} \mathrm{C} / \mathrm{s}$; and a typical M/A constituent indicated by: (d) bright field; (e) dark field; and (f) selected area diffraction pattern. QPF-quasi-polygonal ferrite, GBF-granular bainitic ferrite, $\mathrm{LBF}$ - Lath bainitic ferrite and $\mathrm{M} / \mathrm{A}$ - martensite/austenite.

Figure 6 reveal two types of precipitate embedded in the ferrite matrix, namely Ti-rich $(\mathrm{Nb}, \mathrm{Ti})(\mathrm{C}, \mathrm{N})$ and $\mathrm{Nb}$-rich $(\mathrm{Nb}, \mathrm{Ti})(\mathrm{C}, \mathrm{N})$ particles, with the sizes of $40-80 \mathrm{~nm}$ and 10-30 $\mathrm{nm}$, respectively. The former persisted possibly from the reheating stage and even synthesized during the hot deforming, while the latter mainly formed during the controlled cooling. Some of these fine particles pin dislocations. As Table 3 shows, the average size, $D_{\mathrm{p}}$, and volume fraction, $f_{\mathrm{p}}$, of precipitates in each sample decrease with the increased cooling rate. 

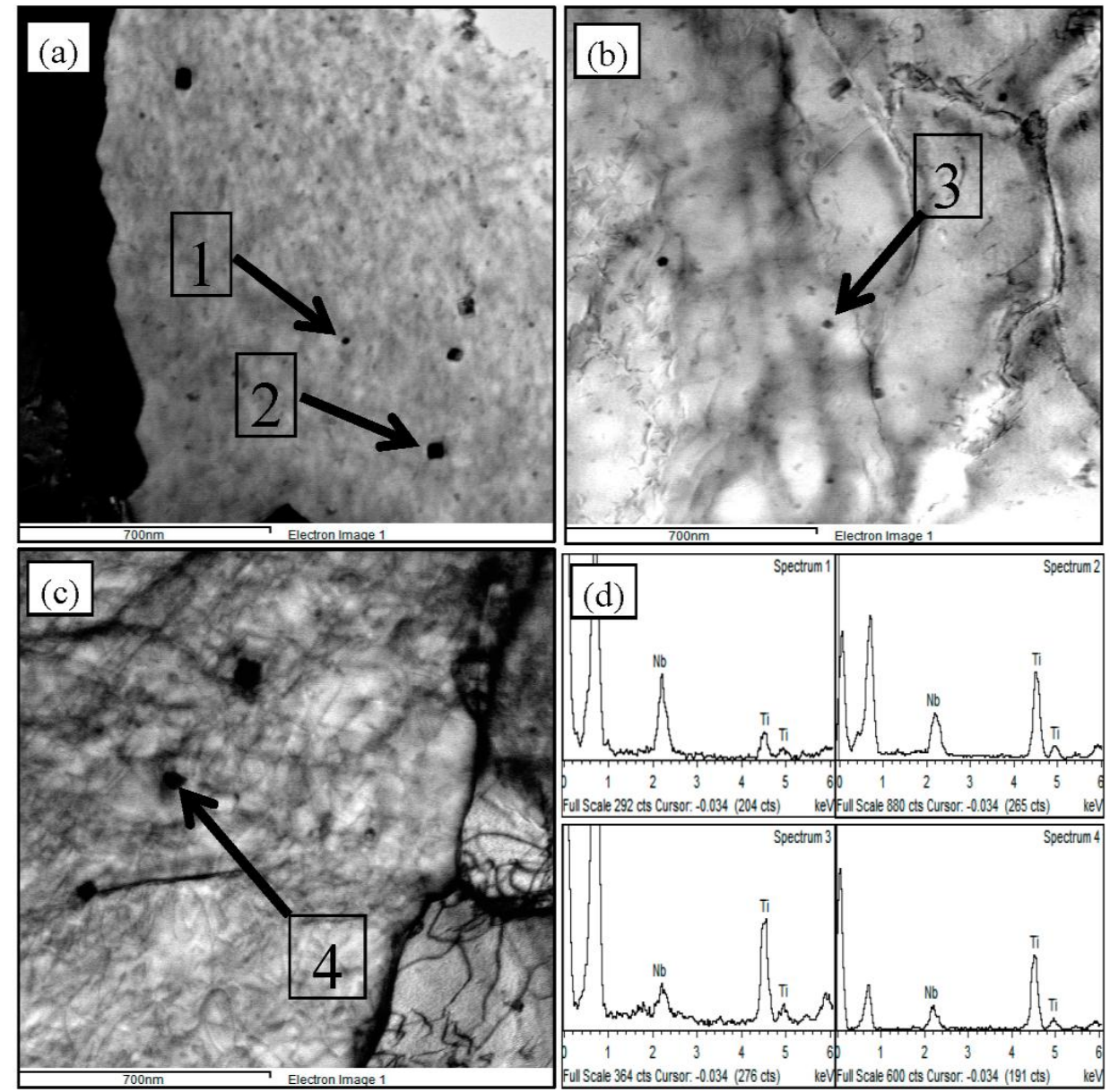

Figure 6. TEM observations of precipitate in samples of: (a) $5{ }^{\circ} \mathrm{C} / \mathrm{s}$; (b) $15^{\circ} \mathrm{C} / \mathrm{s}$; and (c) $20^{\circ} \mathrm{C} / \mathrm{s}$; and (d) their energy dispersive X-ray (EDX) analyses.

Figure 7a,b shows the XRD pattern and its enlarged details for each sample, and the fraction of retained austenite and the dislocation density are summarized in Table 3. As the table shows, both the volume fraction of retained austenite, $f_{\mathrm{RA}}$, and the dislocation density, $\rho$, increase with increased cooling rate.

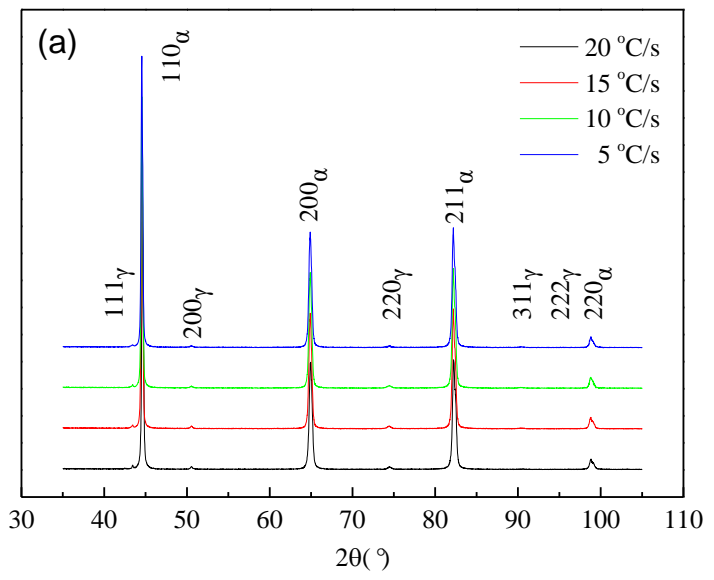

Figure 7. Cont. 


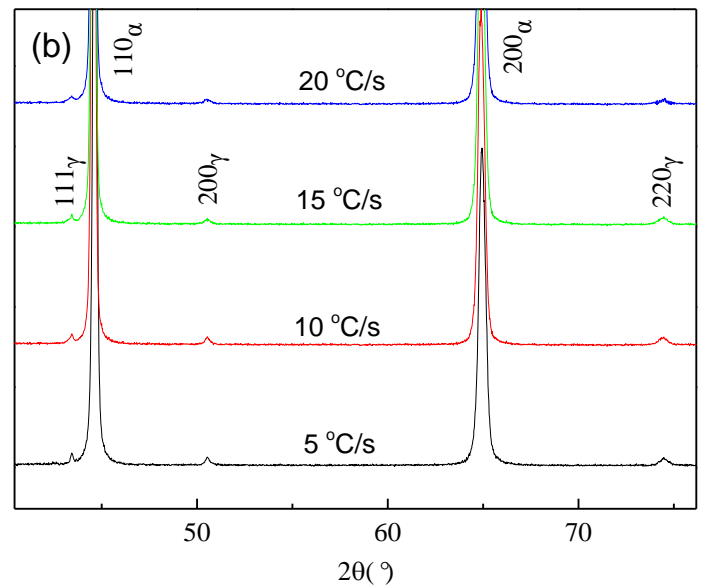

Figure 7. XRD spectra of samples with controlled cooling rate of $5-20^{\circ} \mathrm{C} / \mathrm{s}(\mathbf{a})$; and partial enlarged detail (b).

The MED of the QPF and GBF grains of each sample was estimated using EBSD. The typical inverse pole figures are indicated in Figure 8 and the MED for MTA ranging $2^{\circ}-30^{\circ}$ and varied cooling rate in Figure 9. The MED of the QPF and GBF grains decreases monotonically with decreasing MTA and increasing cooling rate, respectively. Moreover, the boundaries of the QPF and GBF grains can be divided into two categories: high angle $\left(\theta>15^{\circ}\right)$ and low angle $\left(2^{\circ} \leq \theta \leq 15^{\circ}\right)$. The fraction of low-MTA boundaries, $f_{2^{\circ} \leq \theta \leq 15^{\circ}}$, and the corresponding $\mathrm{MED}_{2^{\circ} \leq \theta \leq 15^{\circ}}$ are listed in Table 3 . As the table shows, the former increases, whereas the latter decreases with increased cooling rate.
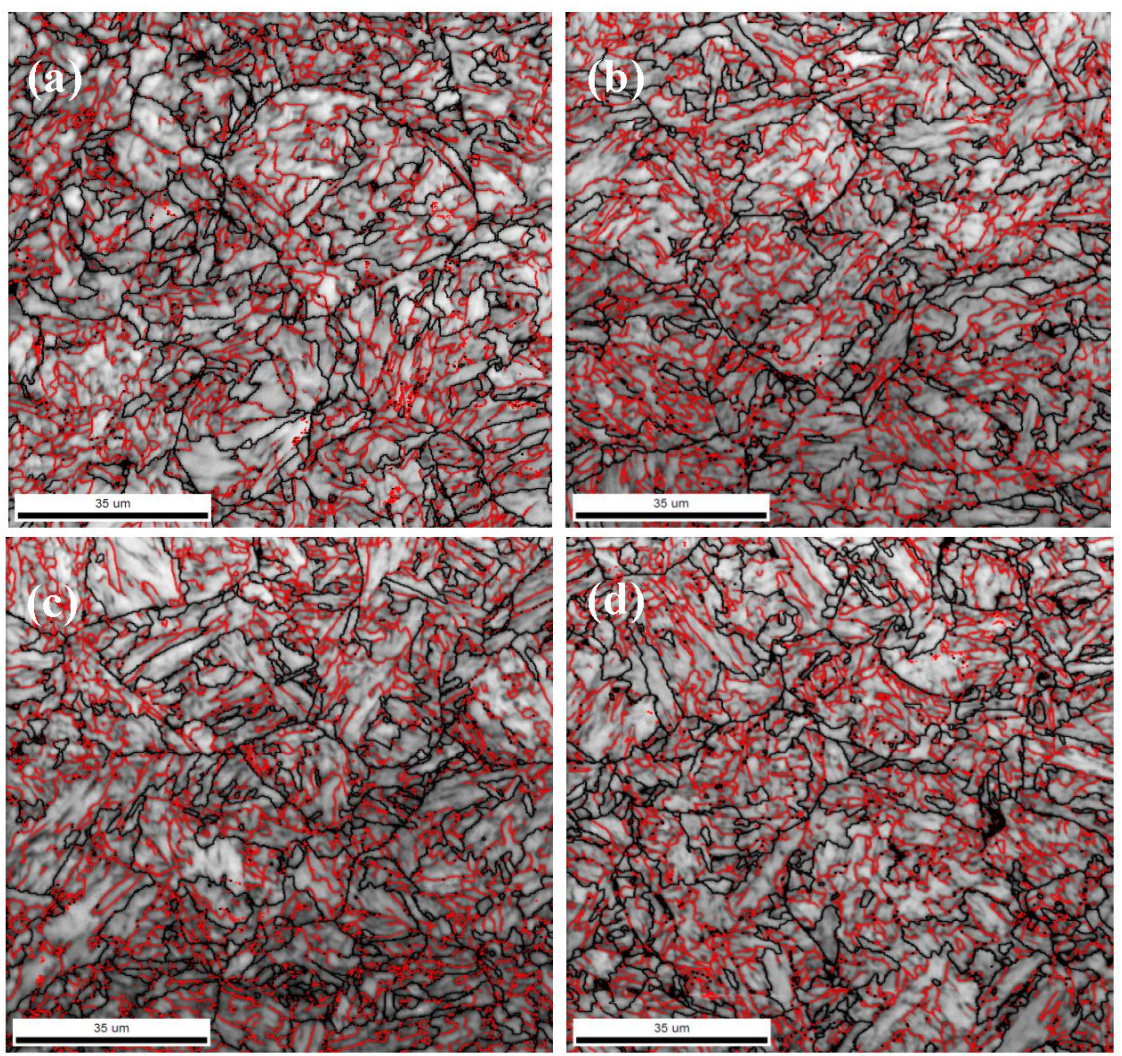

Figure 8. EBSD orientation maps of samples with varied cooling rates: (a) $5{ }^{\circ} \mathrm{C} / \mathrm{s}$; (b) $10{ }^{\circ} \mathrm{C} / \mathrm{s}$; (c) $15^{\circ} \mathrm{C} / \mathrm{s}$; and (d) $20^{\circ} \mathrm{C} / \mathrm{s}$. The red line and the black line represent the misorientation angle in the range $2^{\circ}-15^{\circ}$ and greater than $15^{\circ}$, respectively. 


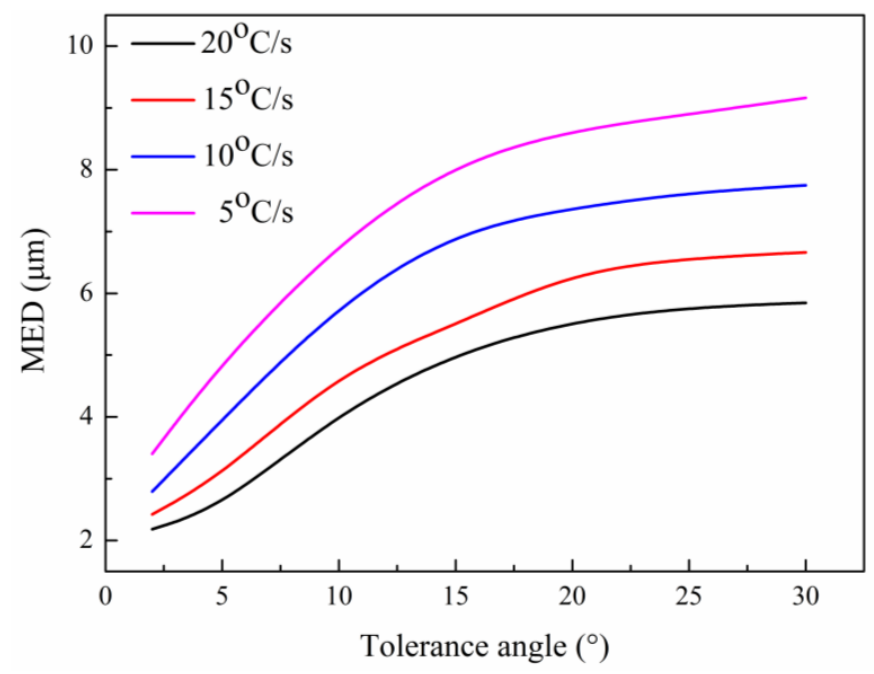

Figure 9. EBSD MED of QPF and GBF grains as a function of MTA and cooling process. MED-mean equivalent diameter, MTA-misorientation tolerance angle, QPF-quasi-polygonal ferrite and GBF-granular bainitic ferrite.

\section{Discussion}

\subsection{Effect of Cooling Rate on the Microstructure}

As Figures 4 and 5 show, a multiphase microstructure consisting of QPF + GBF + M/A constituent formed in each sample, with the quantified attributes summarized in Table 3. Obviously, the GBF increases, whereas the QPF and M/A constituents decrease with increased cooling rate. The mechanism governing the effect of accelerated cooling on this microstructure was determined experimentally.

\subsubsection{Effect of Cooling Rate on the QPF + GBF}

Dilatation curve (Figure 10) was measured during continuous cooling of each sample that was prior imposed by two-pass compressing and initial cooling to $780{ }^{\circ} \mathrm{C}$ as described in Section 2; the starting temperature $\left(\mathrm{Ar}_{3}\right)$ for the transformation of $\gamma \rightarrow$ QPF + GBF in each sample is also indicated in the figure.

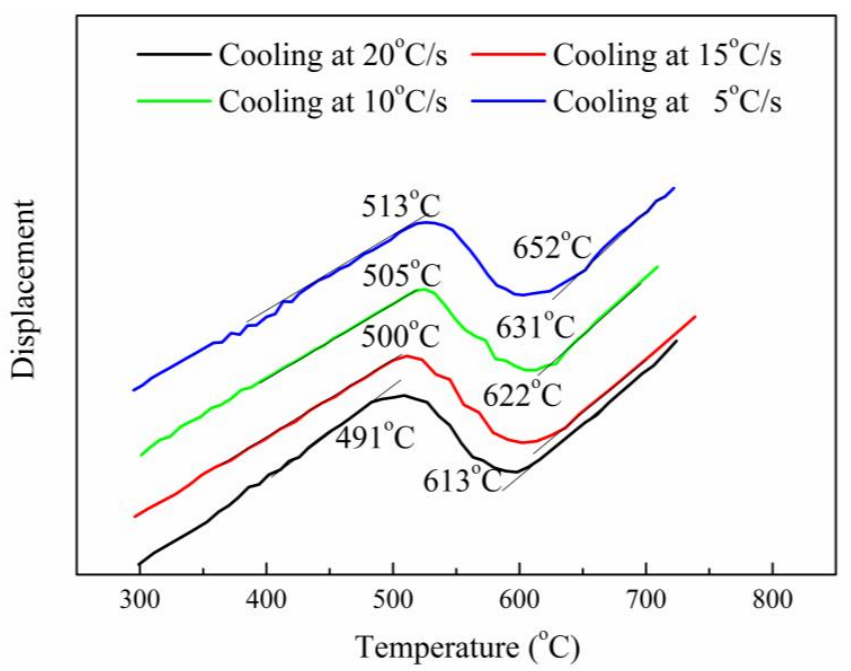

Figure 10. Dilatation curves and $A r_{3}$ and $A r_{1}$ points for samples cooling at different rates. 
As Figure 10 shows, the sample with the highest cooling rate $\left(20^{\circ} \mathrm{C} / \mathrm{s}\right)$ has the lowest $A r_{3}\left(613^{\circ} \mathrm{C}\right)$. As one of transformed products (Figures $4 \mathrm{e}$ and $5 \mathrm{c}$ ) under this highest-rate cooling condition, the GBF, which nucleates and grows mainly from the PAG boundaries in high densities, is the dominant phase of this mixed-microstructure steel. The QPF, in contrast, nucleates and grows intragranually and only in small amounts. Therefore, the thermodynamic driving force for the nucleation of GBF in the sample cooling at $20^{\circ} \mathrm{C} / \mathrm{s}$ is higher than that of the QPF. This result is in agreement with previous works on continuous cooling transformation of bainitic steel [19,25]. Moreover, the $A r_{3}$ increases to 622, 631, and $652{ }^{\circ} \mathrm{C}$, when the cooling rate is lowered to 15,10 , and $5{ }^{\circ} \mathrm{C} / \mathrm{s}$, respectively. This indicates that the $\gamma / \alpha$ transformation in the sample cooling at a lower rate begin at an elevated temperature. In addition, although the GBF is still the dominant phase in the mixed QPF GBF microstructure, the amount of QPF increased significantly with decreased cooling rate. The nucleation and growth of the QPF during slower cooling therefore gradually constitutes the dominant transformation. In addition, QPF mainly nucleates in the dislocation substructure of TMCP-processed steel $[15,18]$ and grows intragranually (Figures 4 and 5); the amount of QPF increases with decreased cooling rate from 20 to $5{ }^{\circ} \mathrm{C} / \mathrm{s}$. The above-mentioned results confirm that the increased cooling rate promoted the formation, and thereby resulted in increasing fractions of GBF.

On the other side, the sample (cooling at $20^{\circ} \mathrm{C} / \mathrm{s}$ ) with the lowest $A r_{3}$ has the highest degree of supercooling for the transformation of $\gamma \rightarrow$ QPF + GBF. This probably leads to the nucleation of the QPF and GBF at the highest rate and results ultimately in the finest equivalent grain. Furthermore, as Figure 8 shows, the accelerated cooling and hence the decreasing $A r_{3}$ brings about a decreasing equivalent grain size of the QPF and GBF (i.e., the MED) at any given MTA.

The dislocation density, $\rho$, in the QPF + GBF matrix of the samples also varies with the $A r_{3}$. That is, the $\rho$ increases with decreasing $A r_{3}$, due to increased cooling rate, which concurs with the works of Bhadeshia et al. [24,26]. In those studies, they proposed that the $\rho$ of bainite increases with decreasing $B_{\mathrm{S}}$ (the starting temperature for bainite transformation), and could be described empirically as a function of the $B_{\mathrm{s}}$, indicating a strong negative correlation between the $\rho$ and the $B_{\mathrm{s}}$.

\subsubsection{Effect of Cooling Rate on the M/A Constituent}

As Figures 4 and 5 show, the amount of QPF in the samples increases with decreased cooling rate. In fact, the surrounded regions by adjacent QPF plates increase with increasing number of growing QPF plates, which leads to an increasing amount of metastable austenite $\left(\gamma^{\prime}\right)$ during the continuous transformation occurred in cooling and subsequent re-reddening. The transition of $\gamma \rightarrow \mathrm{QPF}+\mathrm{GBF}+\gamma^{\prime}$ is, however, accompanied by the diffusion of $\mathrm{C}$ atoms from the QPF and the GBF to $\gamma^{\prime}$. This leads to the C-enrichment of $\gamma^{\prime}$ and correspondingly an increasing amount of M/A constituent with decreased cooling rate, as shown in Figures 4 and 5 and Table 3.

Moreover, the carbon level in M/A (in wt. \%) for each sample with different cooling rate can be estimated by considering the following simplistic carbon balance:

$$
C_{\mathrm{e}}=f_{\alpha} \times C_{\alpha}+f_{\mathrm{M} / \mathrm{A}} \times C_{\mathrm{M} / \mathrm{A}}
$$

where $f_{\alpha}$ and $f_{\mathrm{M} / \mathrm{A}}$ are volume fraction of ferrite and $\mathrm{M} / \mathrm{A}$ constituent $\left(f_{\alpha}+f_{\mathrm{M} / \mathrm{A}}=100 \%\right)$, respectively; $\mathrm{C}_{\mathrm{e}}, \mathrm{C}_{\alpha}$ and $\mathrm{C}_{\mathrm{M} / \mathrm{A}}$ are carbon content in experimental alloy $(0.06 \mathrm{wt}$. \%), and ferrite (assumed to be $0.02 \mathrm{wt} . \%$ ), and M/A constituents, respectively. The estimated results are summarized in Table 3, indicating that the carbon level in M/A constituent increases with increasing cooling rate. Although less $\mathrm{M} / \mathrm{A}$ is present at the highest cooling rate, a larger fraction remains austenite. This result might imply that the thermal stabilization of austenite is enhanced by higher carbon content. Therefore, increased cooling rate can eventually lead to increasing fraction of retained austenite in the M/A constituent, as determined from XRD analyses (Figure 7) and quantifications (Table 3). 
It is worth noting that subsequent to accelerated cooling, the re-reddening process can enhance the diffusion of carbon atoms from the QPF and the GBF to $\gamma^{\prime}$, and accordingly promote the formation of $\mathrm{M} / \mathrm{A}$ constituent and retained austenite in them.

\subsection{Effect of Cooling Rate on the YS}

The final microstructure of the sample, consisting of QPF + GBF + M/A, possesses a variety of microstructural features, such as the effective grain boundaries of the QPF + GBF, dislocations, carbonitride precipitates, and the $\mathrm{M} / \mathrm{A}$ constituent. These features all have the corresponding effects on the YS. Each microstructural feature and its effect on the $Y S$, varies with the cooing rate (Table 2). the $Y S\left(\sigma_{\mathrm{y}}\right)$ of low-C microalloyed bainitic steel can be described by a linear sum of the individual strengthening contributions, according to [19]:

$$
\sigma_{\mathrm{y}}=\sigma_{0}+\sigma_{\mathrm{s}}+\sigma_{\mathrm{d}}+\sigma_{\mathrm{p}}+\sigma_{\mathrm{M} / \mathrm{A}}
$$

where $\sigma_{0}$ is the lattice friction stress; $\sigma_{\mathrm{s}}$ is the solid solution strengthening; $\sigma_{\mathrm{d}}$ is the strengthening originated from the boundaries of the QPF + GBF effective grain; $\sigma_{\rho}$ is the strengthening provided by dislocations of the QPF + GBF; $\sigma_{\mathrm{p}}$ is the carbonitride induced precipitation strengthening; and $\sigma_{\mathrm{M} / \mathrm{A}}$ is the strengthening due to the hard $\mathrm{M} / \mathrm{A}$ constituent. The $Y S$ is contributed by each of these strengthening factors.

The $Y S, \sigma_{\mathrm{y}}$, can be described as a function of the grain size using the Hall-Petch relation $[27,28]$, which is given as follows:

$$
\sigma_{\mathrm{y}}=\sigma_{0}+k_{\mathrm{HP}} d^{1 / 2}
$$

where $k_{\mathrm{HP}} \times d^{-1 / 2}$ and $\sigma_{0}$ are the contributions from boundary strengthening and strengthening provided by other mechanisms, respectively. In this attempt, $k_{\mathrm{HP}}$ is the structural constant that stands for the effect of the effective grain size of matrix QPF + GBF on the strength; $d$ is the effective grain size corresponding to the $\mathrm{MED}_{\theta}$, which represents the MED of the QPF and GBF grains with boundaries at a certain MTA, $\theta$. Low-MTA boundaries can control the movement of dislocations, according to previous works [29,30]. Furthermore, I. Gutierrez [31] proposed that an effective grain with low-MTA boundaries at a threshold angle of $2^{\circ}$, comprises the smallest microstructural unit that controlled the $Y S$. Low angle boundaries $\left(2^{\circ} \leq \theta \leq 15^{\circ}\right)$ are related to the ferrite sub-units within the bainitic packets/sheave, while high angle boundaries $\left(\theta>15^{\circ}\right)$ are relevant to the bainitic packets/sheaves, according to [32]. The effect of MED of QPF grains with MTA ranging $2^{\circ}-30^{\circ}$ on the $Y S$ was also estimated in our previous work, producing a minimum correlation of $95 \%$ between the $Y S$ and $\mathrm{MED}^{-1 / 2}$, for MTA values of $2^{\circ}-6^{\circ}$ [2], which gave a definition of the effective grain size. A similar study was also carried out in the present work. For MTA values of $2^{\circ}-30^{\circ}, \sigma_{y}$ was plotted as a function of $\mathrm{MED}^{-1 / 2}$ for the QPF and GBF grains; for low MTA ranging $2^{\circ}-15^{\circ}, \sigma_{\mathrm{y}}$ exhibited a strong linear relation to $\mathrm{MED}^{-1 / 2}$ with correlation coefficients of $0.95-0.99$. As such, a linear fitting of the $\sigma_{\mathrm{y}} \mathrm{vs}$. $\operatorname{MED}^{-1 / 2} 2^{\circ} \leq \theta \leq 15^{\circ}$ was made for all effective grains with an MTA of $2^{\circ} \leq \theta \leq 15^{\circ}$, as indicated in Figure 11, yielding a correlation coefficient of 0.97 . The obtained linear regression equation is:

$$
\sigma_{\mathrm{d}}=306+420.6 d^{1 / 2}
$$

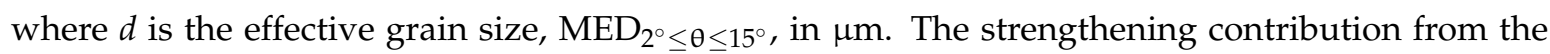
effective grain of the QPF and GBF in the samples cooling at different rates is summarized in Table 4. As the table shows, the contribution from boundary strengthening increases with increased cooling rate, owing to decreasing effective grain size of the matrix QPF + GBF (Table 3). 


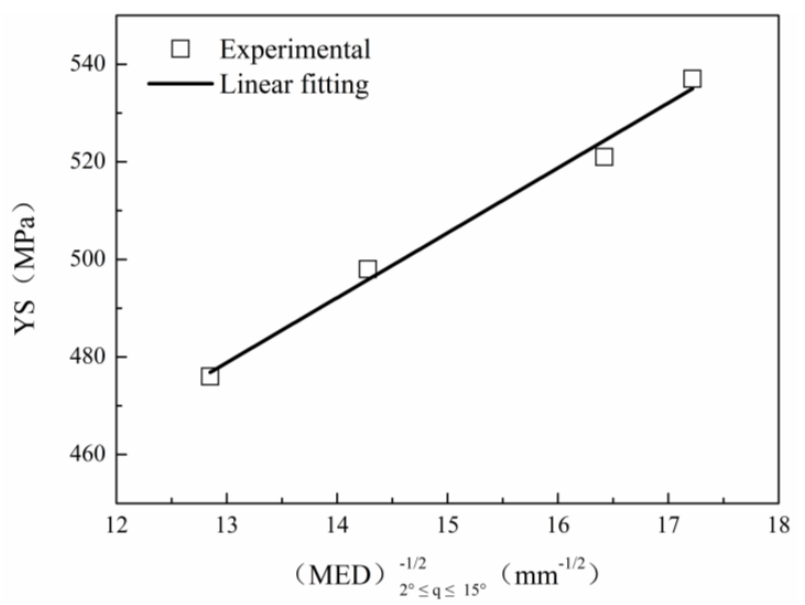

Figure 11. $Y S$ of samples with different nitrogen contents as a function of the reciprocal square root of

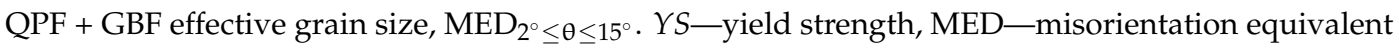
diameter, $\mathrm{PF}$ - quasi-polygonal ferrite and GBF-granular bainitic ferrite.

The estimations on contribution of dislocation strengthening $\left(\sigma_{\rho}\right)$ to the $Y S$ were made according to [32]:

$$
\sigma_{\mathrm{p}}=\alpha M G b \rho^{1 / 2}
$$

where $\alpha, M, G, b$, and $\rho$ are a constant (i.e., 0.15) [32], Taylor factor (2.73 for ferrite steel [32]), shear modulus (81.6 GPa for Fe), Burger's vector $(0.248 \mathrm{~nm}$ for $\mathrm{Fe}$ ), and the average dislocation density, respectively. The value of $\rho$ was determined quantitatively from the XRD spectrum of each sample shown in Figure 7. The strengthening contribution from the dislocations of matrix QPF + GBF to the $Y S$ of each sample is summarized in Table 4. As the table shows, the average dislocation density of matrix QPF + GBF increases with increased cooling rate, thus leading to an increasing contribution from dislocation strengthening.

A high density of small $\mathrm{Nb}$-rich $(\mathrm{Nb}, \mathrm{Ti})(\mathrm{C}, \mathrm{N})$ precipitated particles mainly in ferrite can provide a significant strengthening contribution [33]. Figure 6 and Table 3 confirm that a high volume fraction of Ti- and Nb-rich particles, with average sizes of 16-28 nm, formed in the QPF and GBF matrix of the present $\mathrm{Nb}$-Ti-containing HSLA steel. Therefore, the estimations on strengthening contribution from fine dispersed precipitates must be made, and were performed using the following equation [34]:

$$
\sigma_{\mathrm{ppt}}=\frac{11.3 f_{\mathrm{p}}^{1 / 2}}{D p} \ln (D p / 0.496) \times 10^{3}
$$

where $f_{\mathrm{p}}$ and $D_{\mathrm{p}}$ are the volume fraction and average size (in $\mathrm{nm}$ ) of precipitated particles, as shown in Figure 6 and Table 3 . The contribution of precipitation strengthening to the $Y S$ is summarized in Table 4 . As the table shows, the decreasing cooling rate lead to simultaneous decreases in $D_{\mathrm{p}}$ and increases in and $f_{\mathrm{p}}$ (Table 3 ), thereby resulting in increasing contribution from precipitation strengthening.

In addition to the aforementioned strengthening mechanisms, the sum (110 MPa $\pm 5 \mathrm{MPa})$ of other individual strengthening contributions, $\sigma_{0}+\sigma_{\mathrm{S}}+\sigma_{\mathrm{M} / \mathrm{A}}$, is approximately the same for all the steels considered (Table 4).

Except for the sum $\sigma_{0}+\sigma_{\mathrm{S}}+\sigma_{\mathrm{M} / \mathrm{A}}$, the individual factors can be described in descending order of their strengthening contribution as, effective grain of the GBF and QPF, dislocations and precipitates. In another aspect, the increasing cooling rate led to a decreased density of fine precipitates (Table 3 ) and in turn to a decreased strengthening contribution. However, this increased cooling rate also resulted in simultaneous a decreasing effective grain size of the GBF and the QPF and an increasing dislocation density, yielding in turn an enhanced strengthening contribution. As a result, the overall $Y S$ increases with the increasing cooling rate. 
Table 4. Summary of individual strengthening contributions from different microstructural features of all steels.

\begin{tabular}{cccccc}
\hline $\boldsymbol{C R} /{ }^{\circ} \mathbf{C} / \mathbf{s}$ & $\gamma S / \mathbf{M P a}$ & $\boldsymbol{\sigma}_{\mathbf{0}}+\boldsymbol{\sigma}_{\mathbf{s}}+\boldsymbol{\sigma}_{\mathbf{M} / \mathbf{A}} / \mathbf{M P a}$ & $\boldsymbol{\sigma}_{\mathbf{d}}\left(\mathbf{M E D}_{\left.\mathbf{2}^{\circ} \leq \boldsymbol{\theta} \leq 15^{\circ}\right) / \mathbf{M P a}}\right.$ & $\boldsymbol{\sigma}_{\boldsymbol{\rho}} / \mathbf{M P a}$ & $\boldsymbol{\sigma}_{\mathbf{p p t}} / \mathbf{M P a}$ \\
\hline 5 & 476 & 106 & 171 & 163 & 36 \\
10 & 498 & 110 & 190 & 169 & 29 \\
15 & 521 & 107 & 218 & 171 & 25 \\
20 & 537 & 115 & 229 & 175 & 18 \\
\hline
\end{tabular}

$C R$-cooling rate, $Y S$-yield strength, $\sigma_{0}+\sigma_{\mathrm{s}}+\sigma_{M / A}$-sum of strengthening contribution from lattice friction stress, solid solution and M-A constituent, $\sigma_{\mathrm{d}}$-boundary strengthening, $\mathrm{MED}_{2^{\circ} \leq \theta \leq 15^{\circ}}$-mean equivalent diameter of ferrite grain with boundaries at misorientation tolerance angle $2^{\circ}-15^{\circ}$ determined as the effective grain size, $\sigma_{\rho}$-dislocation strengthening, and $\sigma_{\mathrm{ppt}}$-precipitation strengthening.

\subsection{Effect of Cooling Rate on the TS and YR}

The TS and YS simultaneously decrease with decreasing cooling rate, as shown in Figure 3 and Table 2; the YS decreases, however, in a magnitude higher than the TS. Accordingly, the strain-hardening magnitude $\Delta \sigma$ increases, whereas the $Y R$ decreases, indicating an improved capacity for work-hardening or an enhanced resistance to overloading. This also indicates an enhanced integrity of the steel structure for unexpected deformation [35] and an improved tolerance for defects [36], from an engineering viewpoint.

The final microstructure of the steels with different cooling rates, as shown in Figures 4 and 5, is a mixture of QPF $+\mathrm{GBF}+\mathrm{M} / \mathrm{A}$ constituent. the micro-hardness of the M/A constituent is higher than that of the bainitic ferrite matrix, according to previous studies [16,37]; The M/A constituent can act as a mixed hard phase during tension, and hence induce a high degree of plastic deformation of ductile ferrite phase via two- or three-stage work-hardening, according to the mechanism of typical dual-phase steel [38]. Therefore, the overall strain-hardening capacity can be improved by increasing the amount of hard phase [35,38].

The effect of M/A constituent on the $\Delta \sigma, T S$, and $Y R$ of the samples was also estimated intuitively. As Figure 12 and Table 3 indicate, the area fraction of M/A constituent, $f_{\mathrm{M} / \mathrm{A}}$, increases from $3.5 \%$ to $7.7 \%$ with decreasing cooling rate from 20 to $5{ }^{\circ} \mathrm{C} / \mathrm{s}$, correspondingly, the $\Delta \sigma$, in turn, increases with increasing $f_{\mathrm{M} / \mathrm{A}}$, and effective grain size of GBF and QPF. Accordingly, the $Y R$ declines. The decreasing $Y R$ suggests that the TS decreases much slower than the $Y S$ with increasing effective grain size, due to decreasing cooling rate. This is mainly because the TS is less sensitive to grain size than the $Y S[39,40]$. Nevertheless, the results revealed that the overall tensile properties including the $\Delta \sigma, T S$, and $Y R$ can be regulated with the cooling rate properly controlled.

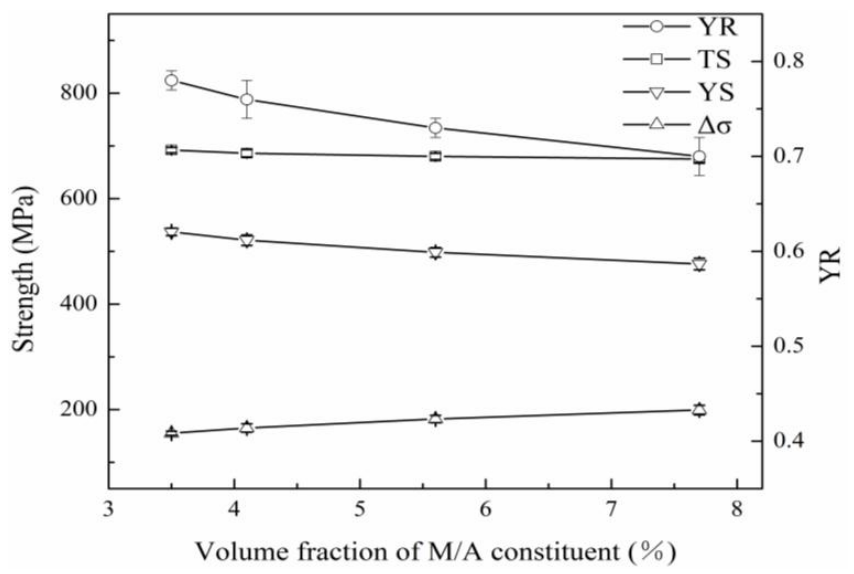

Figure 12. TS, $Y S, \Delta \sigma$ and $Y R$ of experimental steels varied with the area fraction of $M / A$ constituent, $f_{\mathrm{M} / \mathrm{A}}$. TS - tensile strength, $Y S$-yield strength, $\Delta \sigma$-strain hardening magnitude, $Y R$-yield-to-tensile strength ratio and $\mathrm{M} / \mathrm{A}-$ martensite/austenite. 


\section{Conclusions}

The effect of controlled cooling on the microstructure and tensile properties of low $\mathrm{C} \mathrm{Nb}-\mathrm{Ti}$ containing HSLA steel undergoing a group of simulated TMCPs has been investigated. The conclusions are made as follows:

(1) The microstructure consisting of QPF + GBF + M/A constituent forms in samples with varied cooling rate of $5-20^{\circ} \mathrm{C} / \mathrm{s}$. The $\mathrm{Ar}_{3}$ decreased with increasing cooling rate, resulting in increasing $\mathrm{GBF}$, and decreasing QPF and M/A constituents.

(2) The increasing cooling rate reduces the precipitation of fine particles, but leads to a decreasing effective grain size of GBF and QPF, and an increasing density of dislocations, thereby resulting in an increase in the overall $Y S$.

(3) The decreasing cooling rate leads to increased amounts of M/A constituent, and hence an improved overall strain-hardening capacity of the multiphase microstructure, accordingly resulting in a lowered $Y R$.

Acknowledgments: This work is supported by the National Natural Science Foundation (Grant No. 51471142 and 51671165) and the Natural Science Foundation-Steel and Iron Foundation of Hebei Province (Grant No. E2013203373), P. R. China.

Author Contributions: Qingfeng Wang and Yi Fan conceived and designed the experiments; Qian Wang performed the experiments; Fucheng Zhang and Hongwu Liu analyzed the data; Tongliang Wang contributed analysis tools; and Qingfeng Wang and Yi Fan wrote the paper.

Conflicts of Interest: The authors declare no conflict of interest.

\section{References}

1. Kim, Y.M.; Kim, S.K.; Lim, Y.J.; Kim, N.J. Effect of microstructure on the yield ratio and low temperature toughness of line-pipe steels. ISIJ Int. 2002, 42, 1571-1577. [CrossRef]

2. Fan, L.; Zhou, D.; Wang, T.; Li, S.; Wang, Q. Tensile properties of an acicular ferrite and martensite/austenite constituent steel with varying cooling rates. Mater. Sci. Eng. A 2014, 590, 224-231. [CrossRef]

3. Tomma, K.; Tanaka, M.; Matsuoka, K.; Kasuya, T.; Kawasaki, H. Development of Application Technologies for Bridge High-performance Steel, BHS. Nippon Steel Tech. Rep. 2008, 97, 51-57.

4. Kimihiro, N.; Kazuyuki, M.; Naoyoshi, T. High performance steel plates for bridge construction-high strength steel plates with excellent weldability realizing advanced design for rationalized fabrication of bridges. JFE Tech. Rep. 2005, 5, 30-36.

5. Tatsumi, K.; Hiroyuki, S.; Yasushi, K. High tensile strength steel plates and welding consumables for architectural construction with excellent toughness in welded joint. JFE Tech. Rep. 2005, 5, 45-52.

6. Ishikawa, N.; Endo, S.; Kondo, J. High performance UOE linepipes. JFE Tech. Rep. 2006, 1, 20-26.

7. Fan, L.; Wang, T.; Fu, Z.; Zhang, S.; Wang, Q. Effect of heat-treatment on-line process temperature on the microstructure and tensile properties of a low carbon Nb-microalloyed steel. Mater. Sci. Eng. A 2014, 607, 559-568. [CrossRef]

8. Zhang, S.; Liu, K.; Chen, H.; Xiao, X.; Wang, Q.; Zhang, F. Effect of increased N content on microstructure and tensile properties of low-C V-microalloyed steels. Mater. Sci. Eng. A 2016, 651, 951-960. [CrossRef]

9. Jang, J.; Ju, J.; Lee, B.; Kwon, D.; Kim, W. Effects of microstructural change on fracture characteristics in coarse-grained heat-affected zones of QLT-processed 9\% Ni steel. Mater. Sci. Eng. A 2003, 340, 68-79. [CrossRef]

10. Komizo, Y.; Fukada, Y. CTOD properties and M-A constituent in the HAZ of C-Mn microalloyed steel. Trans. Jpn. Weld. Soc. 1988, 6, 41-46. [CrossRef]

11. Okada, H.; Ikeuchi, K.; Matsuda, F.; Hrivnak, I.; Li, Z. Metallographic investigation of M-A constituent-toughness deterioration and its improvement of weld HAZ with high heat inputs in 780 and $980 \mathrm{MPa}$ class HSLA steel (Report 2). Trans. Jpn. Weld. Soc. 1994, 12, 236-242. [CrossRef]

12. Kweon, K.; Kim, J.; Hong, J.; Lee, C. Microstructure and toughness of intercritically reheated affected zone in reactor pressure vessel steel weld. Sci. Tech. Weld. Join. 2000, 5, 161-167. [CrossRef] 
13. Tong, M.W.; Venkatsurya, P.K.C.; Zhou, W.H.; Misra, R.D.K.; Guo, B.; Zhang, K.G.; Fan, W. Structure-mechanical property relationship in a high strength microalloyed steel with low yield ratio: The effect of tempering temperature. Mater. Sci. Eng. A 2014, 609, 209-216. [CrossRef]

14. Lambert, A.; Drillet, J.; Gourues, A.F.; Sturel, T.; Pineau, A. Microstructure of M-A constituent in HAZ of HSLA steel welds in relation with toughness properties. Sci. Technol. Weld. Join. 2000, 5, 1-13. [CrossRef]

15. Akselsen, O.M.; Solberg, J.K.; Grong, O. Effects of M-A islands on intercritical HAZ of low carbon microalloyed steels. Scand. J. Met. 1988, 17, 194-200.

16. Xu, W.W.; Wang, Q.F.; Pan, T.; Su, H.; Yang, C.F. Effect of welding heat input on simulated HAZ Microstructure and Toughness of a V-N Microalloyed Steel. J. Iron Steel Res. Int. 2007, 14, 234-239. [CrossRef]

17. Wang, Y.; Wang, Q.; Liu, L.; Xu, W. Fracture mode of martensite-austenite constituents containing multiphase steel controlled by microstructural and micromechanical aspects. Mech. Adv. Mater. Struct. 2015, 22, 591-596. [CrossRef]

18. Ferreira, H.C.; Boratto, F.J.M.; Buono, V.T.L. Determination of low levels of retained austenite in low-carbon high-manganese steel using X-ray diffraction. Mater. Sci. Eng. A 2015, 628, 110-115. [CrossRef]

19. Yakubtsov, I.A.; Poruks, P.; Boyd, J.D. Microstructure and mechanical properties of bainitic low carbon high strength plate steels. Mater. Sci. Eng. A 2008, 480, 109-116. [CrossRef]

20. García-Mateo, C.; Caballero, F.G.; Bhadeshia, H.K.D.H. Mechanical properties of low-temperature bainite. Mater. Sci. Forum 2005, 500-501, 495-502. [CrossRef]

21. Williamson, G.K.; Smallman, R.E. Dislocation densities in some annealed and cold-worked metals from measurements on the X-ray debye-scherrer spectrum. Philos. Mag. 1956, 1, 34-36. [CrossRef]

22. Zare, A.; Ekrami, A. Effect of martensite volume fraction on work hardening behavior of triple phase (TP) steels. Mater. Sci. Eng. A 2011, 528, 422-426. [CrossRef]

23. Bramfitt, B.L.; Speer, J.G. A perspective on the morpholoy of bainite. Metall. Trans. A 1990, 21, 817-829. [CrossRef]

24. Bhadeshia, H.; Christian, J.W. Bainite in steels. Metall. Trans. A 1990, 21, 767. [CrossRef]

25. Yakubtsov, I.A.; Boyd, J.D. Bainite transformation during continuous cooling of low carbon microalloyed steel. Mater. Sci. Technol. 2001, 17, 296-301. [CrossRef]

26. Takahashi, M.; Bhadeshia, H. Model for transition from upper to lower bainite. Mater. Sci. Technol. 1990, 6, 592. [CrossRef]

27. Hall, E.O. The deformation and ageing of mild steel: III discussion of results. Proc. Phys. Soc. Sect. B 1951, 64, 747. [CrossRef]

28. Petch, N.J. The cleavage strength of polycrystals. J. Iron Steel Inst. 1953, 174, 25-28.

29. Kaijalainen, A.J.; Suikkanen, P.P.; Limnell, T.J.; Karjalainen, L.P.; Kömi, J.I.; Porter, D.A. Effect of austenite grain structure on the strength and toughness of direct-quenched martensite. J. Alloy. Compd. 2013, 577, S642-S648. [CrossRef]

30. Olasolo, M.; Uranga, P.; Rodriguez-Ibabe, J.M.; López, B. Effect of austenite microstructure and cooling rate on transformation characteristics in a low carbon $\mathrm{Nb}-\mathrm{V}$ microalloyed steel. Mater. Sci. Eng. A 2011, 528, 2559-2569. [CrossRef]

31. Gutiérrez, I. Effect of microstructure on the impact toughness of Nb-microalloyed steel. Mater. Sci. Eng. A 2013, 571, 57-67. [CrossRef]

32. Iza-Mendia, A.; Gutiérrez, I. Generalization of the existing relations between microstructure and yield stress from ferrite-pearlite to high strength steels. Mater. Sci. Eng. A 2013, 561, 40-51. [CrossRef]

33. Zhang, J.; Ding, H.; Misra, R.D.K.; Wang, C. Microstructural evolution and consequent strengthening through niobium-microalloying in a low carbon quenched and partitioned steel. Mater. Sci. Eng. A 2015, 641, 242-248. [CrossRef]

34. Rosenberg, J.M.; Piehler, H.R. Calculation of the Taylor factor and lattice rotations for bcc metals deforming by pencil glide. Metall. Trans. 1971, 2, 257-259. [CrossRef]

35. Zare, A.; Ekrami, A. Influence of martensite volume fraction on tensile properties of triple phase ferrite-bainite-martensite steels. Mater. Sci. Eng. A 2011, 530, 440-445. [CrossRef] 
36. Langenberg, P. Relation between design safety and $\mathrm{Y} / \mathrm{T}$ ratio in application of welded high strength structural steels. In Proceedings of the International Symposium on Applications of High Strength Steels in Modern Constructions and Bridges-Relationship of Design Specifications, Safety and Y/T Ratio, Beijing, China, 2008; pp. 28-46.

37. Taylor, M.D.; Choi, K.S.; Sun, X.; Matlock, D.K.; Packard, C.E.; Xu, L.; Barlat, F. Correlations between nanoindentation hardness and macroscopic mechanical properties in DP980 steels. Mater. Sci. Eng. A 2014, 597, 431-439. [CrossRef]

38. Hüper, T.; Endo, S.; Ishikawa, N.; Osawa, K. Effect of volume fraction of constituent phases on the stress-strain relationship of dual phase steels. ISIJ Int. 1999, 39, 288-294. [CrossRef]

39. Tang, Z.; Stumpf, W. The effect of microstructure and processing variables on the yield to ultimate tensile strength ratio in a Nb-Ti and a Nb-Ti-Mo line pipe steel. Mater. Sci. Eng. A 2008, 490, 391-402. [CrossRef]

40. Prasad, S.N.; Sarma, D.S. Influence of thermomechanical treatment on microstructure and mechanical properties of $\mathrm{Nb}$ bearing weather resistant steel. Mater. Sci. Eng. A 2005, 408, 53-63. [CrossRef]

(C) 2017 by the authors; licensee MDPI, Basel, Switzerland. This article is an open access article distributed under the terms and conditions of the Creative Commons Attribution (CC-BY) license (http://creativecommons.org/licenses/by/4.0/). 